\title{
Observations on the Progeny of Alloxan- or Streptozotocin-Diabetic Rats Cured by Pancreatic Transplantation
}

Dear Sir,

In 1973 Lazarow et al. [1] reported that the offspring of alloxan-diabetic female animals showed degranulation and glycogen infiltration of their pancreatic $B$ cells lasting for up to 10 days after delivery, and were of low birth weight. After 3-5 months these progeny exhibited decreased glucose tolerance without transition into manifest diabetes. I was able to confirm this last observation, and also noted a high perinatal mortality among offspring of both alloxan and streptozotocin-diabetic mothers, despite preservation of maternal instincts. The excess mortality appeared to result both from an increase in numbers of congenitally malformed, underweight or overweight offspring, and from failure of suckling.

Streptozotocin is not only a diabetogenic antibiotic, but also a mutagen-carcinogen, inducing renal tumours and nesidiomas in rats [2]. This raises the possibility that the abnormalities observed in the offspring of these diabetic animals might be mutagenic effects of the drugs rather than resulting from the diabetes itself. In view of this, I decided to investigate whether normal fertility, pregnancy and progeny could be achieved by insulinogenic grafts curing alloxan or streptozotocin diabetes in both parents.

Male and female Wistar rats, inbred in my laboratory, were made diabetic by alloxan or streptozotocin (blood glucose $>20 \mathrm{mmol} / \mathrm{l}$ ) and cured by renal subcapsular transplantation of neonatal pancreases from the same family [3]. Three pairs were then mated and their progeny followed for up to five generations. In each generation neonatal abnormalities were recorded, and postprandial blood glucose was measured once weekly for the first 1-2 months. Thereafter IV glucose tolerance tests were performed monthly, using $10 \%$ glucose $(1 \mathrm{~g} / \mathrm{kg})$ into the tail vein of conscious rats fasted for $24 \mathrm{~h}$, with blood samples at $0,15,30,60$ and $120 \mathrm{~min}$. Blood glucose was estimated by a glucose oxidase/peroxidase technique and the assimilation constant of excess glucose was calculated $\left(\mathrm{K}_{\mathrm{G}}\right.$; normal value $\left.>3.0\right)$.

One family of rats has been observed for five generations. Both parent animals had fully established streptozotocin diabetes with hyperglycaemia $26-33 \mathrm{mmol} / 1$. The male then received three 18 day fetal pancreatic grafts and was cured. The female received four pancreases from her own one-day-old neonates and was partially cured $\left(\mathrm{K}_{\mathrm{G}}: 1.1\right.$ to 2.2$)$. Mating took place 8 months later and was followed in due course by parturition. Twenty-two months after grafting, the pancreatic transplant was removed from this female, which again became diabetic and died soon afterwards.
In the first generation of offspring (F1), the effect of previous diabetes was still apparent in the small number of neonates (three), of which one male was a macrofetus $(7 \mathrm{~g})$ and died. The remaining male and female mated and gave birth to the first litter of F2, which died. The second litter of F2 was metabolically nor$\mathrm{mal}$ at 2 weeks and at 3,4 and 5 months of age. The F3 and F4 generations were followed up for 6 and 13 months respectively with no evidence of metabolic abnormalities (mean $\mathrm{K}_{\mathrm{G}}$ for each litter: 3.0 to 4.0 ). The F5 generation was also normal at 1 month (blood glucose: $5.8 \pm 1.3 \mathrm{mmol} / \mathrm{l}, 2 \mathrm{~h}$ after feeding). Growth was satisfactory in all surviving offspring. In the other two families there was impaired fertility.

The results show that streptozotocin-diabetic rats are able to bring forth and suckle their progeny, after cure of the diabetes by intrafamiliar renal-subcapsular transplantation of neonatal or fetal pancreases. Genetic 'clearing' may be the explanation for the perinatal death of some offspring in $\mathrm{F} 1$ and $\mathrm{F} 2$ generations, but their litter mates and subsequent generations up to F5 exhibited normal growth and normal glucose tolerance.

\section{R. Korec}

\section{References}

1. Lazarow A, Wells LJ, Carpenter AM, Hegre OD, Leonard RJ, McEvoy RD (1973) Islet differentiation, organ culture and transplantation. Diabetes 22: 877-912

2. Rakieten N, Gordon BS, Beaty A, Cooney DA, Davis RD, Schein PS (1971) Pancreatic islet cell tumors produced by the combined action of streptozotocin and nicotinamide. Proc Soc Exp Biol (NY) 137: 280-283

3. Korec R (1977) The cure of streptozotocin diabetes in rats by homotransplantation of isolated, intraportally injected Langerhans islets or by renal-subcapsular transplantation of neonatal pancreases. Diabetologia 13: 409-410

Prof. MUDr. Rudolf Korec

Pokroku 4

CS-04011 Kosice, Czechoslovakia 